\title{
How Is Spirituality Part of People's Meaning System?
}

\author{
Nicoline F. Uwland-Sikkema and Anja Visser \\ Helen Dowling Institute, Centre for Psycho-Oncology, \\ Bilthoven, the Netherlands
}

\author{
Gerben J. Westerhof \\ University Twente
}

\author{
Bert Garssen \\ Helen Dowling Institute, Centre for Psycho-Oncology, Bilthoven, the Netherlands
}

\begin{abstract}
Various authors in research on coping advise us to study spirituality from a meaning system perspective. In this approach spirituality is viewed as a part of people's global meaning; an overarching framework of beliefs, goals, and sense of meaning. However, little is known about how spirituality is related to other global meanings to form this meaning system. Therefore, we have explored spirituality and its relationship with other possible elements of the meaning system in interviews with 20 persons, one year after their cancer diagnosis. Applying thematic analysis to analyze the interviews, a typology was developed based on two criteria: (a) the prevalence of spiritual meanings in the interview, and (b) the degree of co-occurrence between spiritual and general meanings. Four types of meaning systems were distinguished: (a) spirituality as an overarching theme that seems to infuse all aspects of the person's meaning system, (b) spirituality as a theme in the background of the meaning system portrayed by a supporting God, (c) spirituality as a hidden theme that is expressed by a transcendent image and experience of oneself, or (d) spirituality as separate from other elements of the individual's meaning system, if described at all. A comparison with quantitative measures of religiosity and spirituality supported the qualitative differences between the four types. This typology can be used to further understand individual differences in adjustment to cancer.
\end{abstract}

Keywords: spirituality, meaning system, coping through meaning making, qualitative research, cancer

Supplemental materials: http://dx.doi.org/10.1037/re10000172.supp

It is becoming increasingly clear that religion and spirituality are related to how well a person adjusts to the diagnosis and treatment of cancer (Aldwin, Park, Jeong, \& Nath, 2014; Salsman et al., 2015). However, the exact role that religion and spirituality play in the adjustment to cancer remains unclear (Aldwin et al., 2014).

In a recent project we set out to investigate the relationship between spirituality and well-being among patients who were receiving medical treatment with curative intent. As a part of this project, we interviewed several of the participants, to learn more

This article was published Online First March 15, 2018.

Nicoline F. Uwland-Sikkema and Anja Visser, Helen Dowling Institute, Centre for Psycho-Oncology, Bilthoven, the Netherlands; Gerben J. Westerhof, Department of Psychology, Health, and Technology, University Twente; Bert Garssen, Helen Dowling Institute, Centre for PsychoOncology, Bilthoven, the Netherlands.

Anja Visser is now at the faculty of Theology and Religious Studies, University of Groningen, the Netherlands.

This work was funded by the Dutch Cancer Society (Grant HDI20084076), We thank Gerlinde Mateboer, Eline Lankamp, Mireille Fikse, Joost Bruggeman, and Floor van de Water for their assistance in the qualitative analysis of the data.

Correspondence concerning this article should be addressed to Nicoline F. Uwland-Sikkema, who is now at the (elderly) care organisation Viattence, Heerde, Eperweg 33, 8181 ET Heerde, the Netherlands. E-mail: nf.uwland@gmail.com about the role that spirituality played in their adjustment process. During data analysis, we came to realize that spirituality could best be viewed in terms of a meaning system and that there seemed to be a difference among participants in how spirituality was positioned within their meaning system(s).

These findings are in line with qualitative research that shows that spirituality is often an important source for finding meaning in the experience of a life-threatening illness, which provides opportunities for stress-related growth (Albaugh, 2003; Ardelt, Ai, \& Eichenberger, 2008; Blow et al., 2011; Ferrell, Grant, Funk, OtisGreen, \& Garcia, 1998; Gall \& Cornblat, 2002; Gockel, 2009; Remondes-Costa \& Lopes, 2014; Tanyi \& Werner, 2008; Trevino, Archambault, Schuster, Hilgeman, \& Moye, 2011). In addition, several theorists have advised that, to understand the role of spirituality in coping, spirituality and religion should be studied from a meaning system perspective (McIntosh, 1995; Pargament, 1997; Park, 2013; Silberman, 2005).

An important concept in this meaning system perspective is "global meaning" (Park, 2010). Global meaning is described as an individual's framework of beliefs, goals, and a sense of meaning. Through this framework, people structure their lives and assign meanings to specific experiences. Global beliefs are assumptions that people make regarding their own nature as well as their understanding of other people, including beliefs regarding selfidentity, control, and justice. Global goals are high level ideals, states, or objects toward which people work, or which they seek to 
maintain, such as health, relationships, or work. A sense of meaning refers to feelings of "meaningfulness," which may be derived from seeing one's action as oriented or making progress toward a desired future goal (Park, 2010; Park \& Edmondson, 2011).

It is assumed that spirituality can inform all aspects of people's global meaning by shaping beliefs (e.g., the nature of God and humanity, control, destiny, karma) and providing ultimate motivation and primary goals for living and guidelines for achieving those goals, along with a deep sense of purpose (Park, 2013), experienced through a religious tradition, or-increasingly in secular Western culture - through meditation, nature, or art (Peteet \& Balboni, 2013). Reed (1992) defined spirituality on the basis of conceptual, empirical, and clinical nursing literature as

the propensity to make meaning through a sense of relatedness to dimensions that transcend the self in such a way that it empowers and does not devalue the individual. This relatedness can be experienced intrapersonally (as a connectedness within oneself), interpersonally (in the context of others and the natural environment) and transpersonally (referring to a sense of relatedness to the unseen, God, or power greater than the self and ordinary source). (p. 350)

We consider spirituality and religion as overlapping, though separate constructs. Religion places spirituality in the context of the beliefs, values, and practices of an organized institution, but spirituality can also be experienced outside of a religious context (Belzen, 2004; de Jager Meezenbroek et al., 2012).

It is also assumed that the centrality or embeddedness of both spirituality and religion within the individual's global meaning determines how well spirituality/religion functions in the coping process (James \& Wells, 2003; McIntosh, 1995; Pargament, 1997). James and Wells (2003) argue that for people for whom spirituality/religion is salient in their global meaning and who are deeply committed to their beliefs, the explanation offered by their spiritual/religious beliefs provides an understanding and acceptance of life events. However, for individuals whose spiritual/religious beliefs are less salient, these explanations may not provide certainty and pose further questions, leading to more distress than in people with a salient belief or no belief. A better understanding of the interplay between spiritual and other global meaning elements will broaden our understanding of individual differences in meaning making and coping with life events; not only between spiritual and nonspiritual persons, but also within spiritual persons themselves (Park \& Edmondson, 2011). In this paper, we make a first attempt to understand the position of spirituality in the meaning system of people with cancer.

\section{A Typology of Meaning Systems}

Several ways are described in the literature to investigate the position of spirituality in people's meaning systems. The first is to form four groups based on whether a person identifies himself/ herself as spiritual, religious, both or neither, and to compare the centrality and content of the (spiritual) beliefs, attitudes, experiences, and practices of these people. Although this is a practical approach, findings by Berghuijs and colleagues (Berghuijs, Pieper, \& Bakker, 2013) among a Dutch sample indicate that information might be missed with this typology. They identified two different clusters within the 'both religious and spiritual' category: Some people combined a strong focus on traditional religion with an interest in new spirituality, whereas other people are strongly involved in new spirituality.

A second approach is to have people fill out a number of different questionnaires on religion and spirituality and to form a typology on the basis of statistical analysis, most often cluster analysis. This has been the predominant approach so far (Klemmack et al., 2007; Park et al., 2013; Riley et al., 1998; Roh, Lee, Lee, \& Martin, 2014; Salas-Wright, Vaughn, Hodge, \& Perron, 2012; Unterrainer, Ladenhauf, Wallner-Liebmann, \& Fink, 2011). However, several of these studies (Park et al., 2013; Roh et al., 2014; Salas-Wright et al., 2012) did not yield the promised typology, because the typology could, instead, be conceived as an artificial categorization of continuous variables of religion or spirituality (Garssen, Visser, \& Uwland-Sikkema, 2015).

Instead, we developed a typology based on how people describe their beliefs and goals in life using qualitative analysis of interviews. The advantage of a qualitative approach is that there is more opportunity for unanticipated combinations of beliefs, experiences, and attitudes to arise. We also checked whether this qualitatively developed typology is supported by quantitative data, using four sources of information: (1) one's religious affiliation, (2) level of self-identification as a spiritual and/or religious person, (3) the person's scores on a spirituality questionnaire, and (4) evaluations of the person's spirituality by raters based on the interview transcripts.

The research questions in the present study are: (a) Which type of meaning systems can be distinguished, and what is the place of spirituality in these meaning systems? (b) What is the relationship between the qualitatively developed typology and the persons' level of spirituality and religiosity as determined by quantitative methods?

\section{Method}

\section{Design}

The interviewees of this mixed-methods study were selected from a large sample of cancer patients. The qualitative analysis of the interviews resulted in a typology of meaning systems. In addition, we tested if these qualitatively developed types of spirituality could be distinguished on the basis of quantitative measures of spirituality and religiosity.

\section{Participants}

Participants were recently diagnosed with cancer and were treated for this disease with curative intent. Persons 18 years of age or older, with any type of cancer except brain cancer were eligible for the study. Excluded were persons with a known psychiatric disorder. Ethical permission for the mixed-methods study was received from the Ethical Review Board of the University Medical Centre Utrecht, the Netherlands.

\section{Procedure}

Eligible patients were recruited by the medical staff of four hospitals and two radiotherapy institutions in the Netherlands. If the patient was interested in participation, the staff member provided him/her with an envelope that contained a description of the 
study, an informed consent form, and a return envelope. On the informed consent form, the participant could indicate whether he or she was willing to be interviewed after having completed the last quantitative assessment. The quantitative assessments took place approximately 2 months after diagnosis, 6 months later, and 12 months later. All participants received a gift certificate of 7.50 euros with the first questionnaire. The interviewees received an additional gift certificate of 10 euros.

In the overall study, we attempted to reduce a selection bias based on spiritual involvement by urging the members of the medical staff to approach all patients, and certainly not only those patients with an open mind with respect to spirituality. The information sheet for eligible patients included the following sentences:

Everyone who is treated for cancer is cordially invited to participate in this study. Even if you consider spirituality to be a vague concept or if you feel that's 'not my sort of thing' you can contribute to the study.

At enrolment 313 of the 460 study participants (68\%) provided informed consent for an interview. At the final measurement moment potential interviewees were selected through purposive sampling, with the intent to maximize the variance in spirituality and well-being among the interviewees. Purposeful sampling is widely used in qualitative research for the identification and selection of information-rich cases related to the phenomenon of interest (Palinkas et al., 2015). We believed that purposeful sampling would allow us to contrast the experiences of people and understand more clearly whether spirituality provides something unique to the process of adjustment to cancer.

After eligible participants had completed the final assessment, a profile was made based on the quantitative data they had provided throughout the study. The profile included the person's age, gender, religious affiliation, self-reported spirituality and religiosity, type of cancer, scores on a spirituality questionnaire, a well-being questionnaire, and a distress questionnaire. If a profile stood outfor example, the person scored high on spirituality but low on well-being/high on distress, or showed a marked change in spirituality or well-being/distress-the person was selected to be interviewed.

During selection it was attempted to avoid the overrepresentation of women, certain types of cancer, and certain religious affiliations, so the participants would also be representative of the overall study sample. When a participant was selected based on his or her profile, the researcher called the person by telephone to ask whether the participant was still willing to be interviewed, and, if so, to provide any additional information he or she might need and to schedule an appointment. In order to avoid selection bias at this stage, we invited the participants for an interview about their experiences of the past year, not specifically about spirituality. Over the entire study period, 25 persons were selected to be interviewed, of which five refused for various reasons (response rate $=80 \%$ ). The characteristics of the participants are presented in Table 1 in the online supplemental materials.

\section{Measures}

Interviews. The in-depth interviews followed a semistructured topic list with three main topics: the experience of cancer, attitude in life, and spirituality. The interview method was tested on three cancer patients who had not taken part in the quantitative study. The topic list was designed to first elicit a narrative on how the person had experienced the diagnosis and treatment of cancer, using the question: "Can you describe the past year to me"? To help the person to tell this narrative the interviewer used several extra questions such as: "What gave you strength?" or "What changed in your life?" Next, the person's attitude in life was addressed more explicitly with the question "How would you describe your attitude in life?" in case the person had not brought this up already. Then, the interviewer asked more specifically about what is important in his or her life, how the participant views difficulties in life, and what gives them feelings of trust. The third topic involved the interviewee's personal definition and experience of spirituality. Until that point the word "spirituality" was not mentioned by the interviewer, unless the participant had used it himself/herself. We chose to explicitly discuss spirituality only at the end of the interview, because we wanted to reduce the chance of creating a bias in the person's descriptions of his or her life attitude and the role that it had played in the experience of cancer.

The interviews lasted on average two hours, ranging from $1 \mathrm{hr}$ to $2 \mathrm{hr} 45 \mathrm{~min}$. All interviews took place at the participant's home. To ensure anonymity, all names in the quotes of interviewees used in this report are fictional names.

\section{Questionnaires.}

Religious affiliations or life-philosophy. The participant's religious affiliations or life philosophy was assessed with the question: "With which church or life-view do you feel affiliated; none, Roman Catholic, Protestant, Judaism, Islam, Buddhism, Hinduism, Humanism or other?"

Self-reported level of spirituality and religiosity. The participant's level of spirituality and religiosity (Questions: "Do you consider yourself to be a religious person/Do you consider yourself a spiritual person?") was measured on a 5-point scale ( $1=$ definitely not, $2=$ not really, $3=I$ doubt it, $4=$ somewhat, and $5=$ definitely).

Spiritual involvement. The participant's spiritual involvement was assessed with the Spiritual Attitude and Involvement List (SAIL; de Jager Meezenbroek et al., 2012). This 26-item questionnaire consists of six subscales that assess the experience of meaning and purpose in life, an attitude of acceptance, an attitude of caring for others, the experience of connectedness with nature, transcendent experiences, and spiritual activities. A question is, for example: "I experience the things I do as meaningful." Its reliability and validity were sufficiently demonstrated among five different samples (de Jager Meezenbroek et al., 2012). The internal consistency of the subscales in the current study ranged from Cronbach's alpha .73 to .87 . In addition, three researchers independently assessed the level of spirituality on a 5-point scale $(1=$ no reference of spirituality; $5=$ very spiritual) after having read each interview entirely.

Well-being. The participant's well-being was measured with the Health and Disease Inventories subscale Joy in Life (Cronbach's alpha $=.82$; de Bruin, van Dijk, \& Duivenvoorden, 1996), and distress with the Hospital Anxiety and Depression Scale (Cronbach's alpha $=.89-.90 ;$ Spinhoven et al., 1997). 


\section{Qualitative Analysis}

We conducted a thematic analysis as described by Braun and Clarke (2006). After having conducted 12 interviews, the interviews were transcribed, read, and summarized. One researcher started coding the interviews by developing codes that closely resembled the wording of the interviewees. A difficult decision was whether or not an element in the interview could be labeled as spiritual. The spirituality definition that was our starting point seemed too broad to distinguish spiritual experiences, beliefs, and attitudes from nonspiritual experiences, beliefs, and attitudes in the interviews. Instead, the concept of global meaning (Park, 2010) became an important sensitizing concept for the categorization of these attitudes and beliefs. During discussions among the coauthors, it became clear that most distinctive for spirituality in the interviews were the use of symbolic language and the "transcendent" nature of the described experiences, beliefs, and attitudes. On the basis of this criterion we were able to distinguish spiritual meanings (e.g., spiritual beliefs, attitudes, and experiences) in the interviews that are different from other forms of meanings, which were labeled as "general meanings." When the interviews were compared using this categorization, it appeared that they clearly differed in the frequency with which spiritual meanings were present.

To further validate this idea of spiritual and general meanings, we held another eight interviews. The coding of these interviews led to the final adjustment of the coding scheme. In this phase we discovered that spiritual meanings were related to general meanings and that this relationship differed between participants. The spiritual meanings could color the general meanings, could stand apart from spiritual meanings, or could be virtually absent. This led to the development of a typology of meaning systems. Two criteria became decisive in distinguishing the types of meaning systems: (1) how prevalent spiritual meanings were in the interview, and (2) the degree of co-occurrence between spiritual and general meanings. A description of the resultant four types of meaning systems will be presented in the Results section.

\section{Trustworthiness}

In addition to the procedures described above, the following procedures were used to enhance the trustworthiness of the study:

- A member check was performed with 18 of the 20 interviews by sending the participant a summary of the interview for comment. All confirmed that the interpretation of their cancer experience, life attitude, and spirituality was correct.

- Throughout the analytical process peer debriefing with the advisory board of the mixed-methods study was applied to verify the appropriateness of the analytical procedures, interpretations, and terminology.

- After having developed the typology, its validity was tested by four students in nursing and care ethics. The students were first presented with descriptions of the four meaning systems. Then, each student read 10 interviews; the first pair of student read the same 10 interviews, and the next pair read 10 other interviews. Thus, a total of 20 interviews were judged. Next, they chose which type of meaning system represented an interview the best. They also scored how certain they were of their choice on a 5-point Likert scale. The type of meaning system that had been chosen corresponded with the categorization of the researcher for 15 of the 20 interviews $\left(\chi^{2}=26.67, p<\right.$ $.001)$. This indicates that the students sufficiently recognized the type of meaning systems in the interviews.

\section{Quantitative Analysis}

We also determined whether the set of four meaning systems differed with respect to four other measures of religion and spirituality, namely (1) religious affiliations or life philosophy, (2) self-reported level of spirituality and religiosity, (3) level of spiritual involvement assessed with the SAIL (de Jager Meezenbroek et al., 2012), and (4) level of spirituality as independently assessed by the three researchers after having read each entire interview. A Kruskal-Wallis test was conducted to test whether the types of meaning systems differed significantly on these quantitative measures. If significant, a Mann-Whitney $U$ test was applied to further investigate the differences between the groups.

\section{Results}

\section{Qualitative Findings}

The elements of the meaning system. As a result of the qualitative analysis we identified five spiritual meanings and five general meanings in the interviews as elements of the person's meaning system. These meanings and their subcategories are presented in Table 1.

The five spiritual meanings were not found in all interviews, but the five general meaning were all present in each interview. In some interviews, the general meanings were mentioned without any reference to a spiritual meaning, whereas some interviewees mentioned them in close relationship with spiritual meanings. Especially in interviews where spiritual meanings were very evident, the spiritual and general meaning often co-occurred in the same sentence or the same paragraph. The next quote from Eric, a 67-year-old man with prostate cancer, provides an example of this co-occurrence. In this quote he describes that his purpose in life is to be connected to other people and to do good (general meaning: meaning in life). This purpose includes spiritual meaning, because he describes it in relationship with God and with having received a task in life (spiritual meaning: transcendent image and transcendent meaning in life).

I believe that you are here for a reason and that you do not just live for yourself. For me that is a profound belief. You are here to make something of it with other people. Trying in this country, this province, this town and in your direct neighborhood to be in a good relationship with each other. And if you also believe in God, as I do, then that is the reason I think, because it is what Jesus himself did on earth.

In interviews where spiritual meanings were less prominent, the general meanings were often described without any reference to a spiritual meaning. In the next quote Mark, a 53-year-old man with colon cancer, describes that he doesn't need an answer to existen- 
Table 1

Spiritual and General Elements of the Meaning System

\begin{tabular}{ll}
\hline \multicolumn{1}{c}{ Spiritual elements } & \multicolumn{1}{c}{ General elements } \\
\hline Transcendent Meaning in life & Meaning in life \\
- Staying connected to the Transcendent & - Enjoying life \\
- Having received a task in life & - Being healthy \\
& - Working \\
& - Being good to yourself and others \\
& - Being with loved ones \\
& - Sharing and passing on one's lessons \\
& - Tradition, staying connected to the past \\
Influence of the Transcendent & Control in life \\
- Belief that everything occurs with a reason & - Belief in being in control and responsible \\
- Belief to be guided by the Transcendent & - Belief in the influence of psyche on body \\
- Belief in having an influence on the & - Belief in the influence of one's behavior on health \\
Transcendent & - Belief in having no control over events in one's life \\
Image of the Transcendent & Self-image \\
- Being part of greater whole & - Identity \\
- God (as a person or a higher force) & - Character \\
- Transcendence found in nature & - Image of humanity \\
- Transcendence found in a connection between & \\
people & \\
- Transcendence found in a person & \\
Expectation of a Transcendent future & Attitude toward Suffering and death \\
- Heaven/afterlife & - Illusion of infiniteness and invulnerability \\
- Reincarnation & - Acceptance (or no acceptance) of suffering and \\
- New dimension & finiteness \\
Transcendent experiences & Attitude through experiences \\
- Connectedness with one's body, nature, the & - Trust through experiences \\
Transcendent or other people & - Acceptance through experiences \\
- Awe and beauty & \\
- Ordinary events given a Transcendent meaning & \\
\hline
\end{tabular}

tial questions such as why human beings exist. He strives for maintaining a good life with his loved ones (general meaning: meaning in life), without making any reference to something that transcends his life.

I could be contemplating about everything, from why are humans on earth, what existed first, the chicken or the egg? Yes, I do not want to be engaged in such questions. It is a fact that I exist, and I owe the fact that I am here to my parents. And that my children are here, they owe it to us. And does life have some purpose, something you want to achieve? Well, I've never set a goal of something I wanted to achieve. I live my life, because I have to, because I haven't chosen it, I have received it. And that counts for my children as well. But the only goal I have for myself is that I want to have a good life for myself and my children, and the people I live with. So I am very satisfied and I do not believe that people need more.

\section{Discovering Types of Meaning Systems}

After the classification of the meaning system elements, we developed four types of meaning systems that were defined along two dimensions: (1) the prevalence of spiritual meanings in the interview, and (2) the degree of co-occurrence between the spiritual and general meanings in the interview. The types of meaning systems were named "omnipresent spirituality" (Type 1), "accompanying spirituality" (Type 2), "enclosed spirituality" (Type 3), and "absent spirituality" (Type 4). The differences between the four types of meaning systems are visualized in Figure 1 in the online supplemental materials. In the paragraphs below we will first describe the specific content of each meaning system. Next, we will compare these types of meaning systems with other measures of religion or spirituality.

Type 1: Omnipresent spirituality. Spiritual elements took a central place in the six interviews that belong to this type. Spiritual elements were mentioned spontaneously in the very beginning of the interview, when persons spoke about their cancer experience. general elements, especially their beliefs about meaning in life and control, and attitudes through experience (having trust and acceptance through earlier experiences), were placed in the context of their spiritual beliefs and experiences. Therefore, this type of meaning system was named omnipresent spirituality. The spiritual element transcendent meaning in life was most prominent in the interviews. The participants described that the meaning and purpose in their lives is to stay connected to the Transcendent, and/or to learn lessons from the events in their lives that would bring them closer to reaching their full potential. Various kinds of transcendent images occurred in this type of interviews such as an undefined higher power, a personal God, or a special connection between people. Anna (48-year-old woman with cervix cancer) describes being part of a greater whole:

However, I do not believe in a traditional God, but I do believe in a source, the source of light from which we originate; the source to which we will return, that you and I are both part of. We all are only small manifestations of this enormous source. . . . You can just connect with this light source. Whether it is in me, outside of me, whether you call it God or Buddha or Allah, I do not care, but it is a very concrete experience, and it is mine. 
The participants with this type of meaning system believe that the transcendent guides them, but they also believe that they have an influence on the presence of the Transcendent in their lives. Most often this meant that they emphasized their own responsibility in ensuring that the transcendent is active in their lives by seeking contact, being open to the transcendent, and engaging in spiritual activities. The participants mentioned generally known spiritual activities, such as prayer, yoga or meditation. Two participants also spoke about a practice called "visualization" (visualizing one's desires) assuming that this enabled them to attract positive situations in life. In addition, all the individuals of this type talked about a belief in life after death, which they expressed as a belief in heaven, reincarnation, or a passage to a new dimension.

Type 2: Accompanying spirituality. General meanings took central stage in the six interviews of this type of meaning system. Of these general meanings, the belief "self-image" was most salient. The participants portrayed themselves as optimistic and energetic persons. This did not seem to be related to spiritual meanings at first sight. Only when the participants were asked about what they considered to be the source of their vitality and optimism, spiritual beliefs appeared. The participants talked about the belief that there is a higher power who supports them when they are no longer able to handle a situation by themselves. Ellie, a 64-year-old woman with breast cancer, describes this image of God very clearly, an image that she formed when she was younger and that remained with her throughout her life:

I once made a little poem. It just goes like, let me think: 'I am just Ellie, who travels with me? God himself is my traveling mate. He helps me when my need is great. I am just Ellie, who travels with me'? So, I write that every year in my calendar and yes, that is the way I see it; God as a traveling companion. ... Yes, beside me, or behind me, who catches me when I fall down.

The six people with this type of meaning system defined God as a personal entity, love, or a guiding force. The 'Transcendent Meaning in Life' of these individuals is to stay connected with the transcendent, or to fulfill their life's purpose of being of value to others. They did not talk about a belief of being able to influence the transcendent, but the transcendent could influence them. This is in contrast to the participants in the first type, who talked about a more reciprocal relationship between them and the transcendent. The spiritual activities that they described were foremost prayer, going to church, and remembering an inspirational image or text. Five of the six people within this type also spoke about transcendent experiences such as feeling connected with God, people, or nature. The belief in a life after death varied between these interviewees from experiencing a connection with a deceased loved one, visualizing life after death as the passing into a new dimension, to believing in life after death without a clear image.

Type 3: Enclosed spirituality. In these four interviews the general beliefs about control and meaning in life (being good to others, being with loved ones, and enjoying life), appeared in the forefront. The people of this type expressed the belief they are responsible for and in control of their own lives. They often indicated that earlier experiences in life had strengthened that belief. For instance, John, a 57-year-old man with esophageal cancer said that he had quit his job several times, sold everything and left for a sabbatical with his wife. His experience of being able to start all over again after these sabbaticals, just the way he wanted, supported his trust in being in control of his own life.

Spiritual meanings became manifest only toward the end of the interview when the participant's definition of spirituality was explicitly discussed. The spiritual meanings that appeared in all four interviews were a transcendent image and a transcendent experience. When they talked about these spiritual meanings they related them to their life attitudes. It contrast with the other two types of meaning systems, it was observed that the transcendent only manifests within themselves, or in their connection with other people. For example, when they talked about their self-image, a transcendent image such as a deeper layer of oneself or "an inner essence" on which they relied, emerged. The transcendent experiences that they mentioned were foremost the experience of awe and beauty in life, and feeling connected to other people. Additionally, they did not describe a transcendent meaning in life such as staying connected to the transcendent, or having been given a task in life. However, they could describe their meaning in life with a transcendent connotation (transcendent experience), like Regina, a 45-year-old woman with breast cancer who talks about the importance of music in her life.

Interviewer: You indicate that music touches you deeply and moves you. Can you elaborate on that?

Regina: Well, it's something you cannot put into words, it's beyond words, it's something that touches you in the depths of your soul and that is so vital. You can try to put it into words but you will not succeed. That is when you listen to music, but when you make music and you're a part of it, it's even more intense. .. .

Interviewer: Would you say that making music is the purpose of your life?

Regina: Well, that sounds a bit big, but it is the blood that runs through my veins.

The interviewees with this type of meaning system sometimes described a spiritual activity such as meditating or practicing yoga. Two of the four interviewees within this type mentioned a belief in an afterlife.

Type 4: Absent spirituality. Although the name of this type of meaning system might suggest otherwise, a few spiritual meanings were present in the four interviews that belong to this type. The spiritual meanings that were found were the expectation of a transcendent future or a transcendent experience. For example, Carla, a 50-year-old woman with breast cancer, talks about situations that were experienced as not by accident (transcendent experiences).

Interviewer: So I understand that you do not really consider yourself to be a spiritual person. Do you ever think about it?

Carla: $\quad$ Yes, there are these silly examples of when I'm driving home and think: "I hope that he or she doesn't call asking whether they can come over for a cup of coffee, because I want to do this or that. And then I come home and my husband 
says: "This person has called and she's coming over for coffee tonight." And then I think "Why did I think about that? On moments like that, I think: "Why did I know this?" I cannot explain it but I do not think about it any further either.

Carla talked about this experience of foresight only at the end of the interview, when the interviewer asked her about her definition of spirituality. In contrast to the other three types the persons with this meaning system did not relate these spiritual meanings to their described life views and life attitudes, or to the way they interpreted their cancer experience. Because these spiritual meanings appeared loose in their story we labeled this type as absent spirituality. The general meanings, self-image and meaning in life, seemed most salient in their meaning system. They portrayed themselves as positive and down-toearth people and described that it is very important to them to enjoy life, be healthy, and spend time with their loved ones and to fulfill their jobs.

\section{Quantitative Findings}

The qualitatively determined typology compared with quantitative measures. Based on the description of the four types above, one might suspect that these types merely represent different religious affiliations or levels of spiritual involvement. However, there were no major differences in the distribution of religious affiliations or life-philosophies between the four types (see Table 2 in the online supplemental materials). An exception seems to be the enclosed spirituality type of meaning system (Type 3), which contains no participants who defined themselves as Roman Catholic or Protestant. It appeared from the interviews that for some participants their religious affiliation corresponded with their meaning system, whereas for others it was more a reference to the religious environment in which they had grown up.

We compared our typology with the simpler division into the four categories: "religious and spiritual," "spiritual but not religious," "religious but not spiritual," and "neither religious nor spiritual" (see Table 2 in the online supplemental materials). Individuals of the enclosed spirituality type (Type 3) considered themselves spiritual, but not religious, and individuals of the absent spirituality type (Type 4) fall into the neither religious nor spiritual category. However, there was no correspondence between this categorization and the participants of Type 1 and Type 2 .

Differences between the types were found on the self-reported level of spirituality and religiosity, the researchers ratings of the participants' level of spirituality, and on two of the seven subscales of the SAIL, namely, Meaningfulness and Spiritual Activities (see Table 2 in the online supplemental materials). The mean values of these quantitative measures for each type are depicted in Figure 2 in the online supplemental materials.

Compared with the other three groups, the participants of Type 1 considered themselves most spiritual, experienced the highest level of Meaningfulness, and reported most Spiritual Activities. The participants of the second type considered themselves most religious (although the difference between Type 1 and Type 2 was not statistically significant) and reported more spiritual activities than Type 3 and Type 4 . Type 3 scored similar to Type 4 on their self-reported level of religiosity and the two SAIL subscales (Meaningfulness and Spiritual Activities), but they considered themselves more spiritual than Type 4. Only the researchers' ratings of the participants' spirituality, which they rated after having read the interviews, show a clear declining pattern from Type 1 to Type 4 .

\section{Discussion}

The goal of this qualitative study was to explore the place of spirituality within the meaning system in individuals with cancer. We identified five spiritual meanings and five general meanings. Whether or not a meaning was considered spiritual was determined by the extent to which the participant described his or her belief, attitude, experience or practice as "special," "beyond everyday life experiences," and/or "difficult to put into words."

We classified the interviews into four types of meaning systems on the basis of the presence of the spiritual meanings in the interviews, and the co-occurrence of the spiritual and general meanings. These four types show the different ways in which spirituality can appear in the meaning system: (1) spirituality appears as an overarching set of beliefs, attitudes, and experiences that seems to infuse all aspects of the person's meaning system (omnipresent spirituality); (2) spirituality appears in the background of the meaning system portrayed by a personal and supporting God (accompanying spirituality); (3) spirituality is hidden within the general beliefs, attitudes, and experiences and is expressed by a transcendent image and experience of oneself (enclosed spirituality); or (4) spirituality does not appear or only as a few isolated spiritual experiences and beliefs (absent spirituality).

To the best of our knowledge, a qualitative typology with regard to religion and spirituality has been developed in only one other study (Polzer \& Miles, 2007). However, their typology focuses on the different types of relationship with God and the effect of this relationship on self-management with diabetes, not on the meaning system in general or on the context of cancer.

We have examined how our typology is related to quantitative measures of religiosity and spirituality. Besides the researchers' ratings of the participants' spirituality, the quantitative variables did not show a steadily increasing or declining pattern. This finding may be important when studying the relationship between spirituality and adjustment. Often, this relationship is investigated by measuring spirituality as a continuous variable. However, the qualitative difference in experiences, attitudes, and beliefs between the participants found in this study suggests it could be more fruitful to apply the concept of meaning system types in studying the relationship between spirituality and adjustment. As Park (2010) and others (McIntosh, 1995; Pargament, 1997; Park, 2013; Silberman, 2005) suggest, the process and outcome of adjustment to cancer is likely influenced by the specific content of the global meaning of a person. This typological approach takes this content into account.

Even religious affiliation said little about the type of meaning system of the interviewees and, specifically, whether the spiritual meanings were salient or not. One explanation for this finding is that for some interviewees their religious affiliation was only a reference to the religious environment in which they 
have grown up. These findings support the observation by Molzahn et al. (2012), that a person's religious tradition is not a good indicator of the importance of spirituality for a person and its role in coping with a life-threatening illness. In line with Molzahn et al.'s (2012) findings, we suggest that exploring meaning systems rather than asking someone about his or her religious background may be more effective for understanding the individual's experience of a serious disease. Health care professionals can ask simple questions, such as "What is important in your life that you want to preserve?" or "What have you always put your trust in?" If the professional is acceptant of and attentive to the active elements of the meaning system, the spiritual meanings that are important to the patient will be spontaneously mentioned.

\section{Limitations}

We took a naturalist approach to the narratives of our participants. Nevertheless, we are aware that the narratives were constructed in interaction with the interviewer and were about a specific topic; the experience of cancer. In his dissertation about narrative reconstruction in people dealing with cancer Donders (2004) stresses that telling the story of cancer is a form of coping for the participants; it is part of the process of meaning-making. So, the findings in our study are not only the result of a process that has taken place during the year in which cancer was experienced, but they are also the result of relating the story to the interviewer. We have exclusively studied participants with cancer and the findings might be specific for people experiencing cancer. We would encourage other researchers to study the position of spirituality in meaning systems in other contexts: among healthy people, among patients with other diseases, and among people with other religious backgrounds, or in people from another European or non-European culture.

The representativeness of our findings is also influenced by the sample size and the sampling method. We selected only 20 participants based on a high or low score on spiritual involvement and on well-being or distress. Therefore, it is possible that the differences between the types are overestimated. Further research is needed to explore the representativeness of this categorization.

Finally, because we conducted only one interview with each person, it is uncertain whether the elements of the meaning system and the typology that we found stay stable or change over time.

\section{Conclusion}

Understanding spirituality as part of the meaning making process of people with cancer begins with understanding the meaning system as a whole (general meanings, spiritual meanings, and their coherence). The four types of meaning systems give insight into the different ways that spirituality can be present in an individual's meaning system. The next step is to investigate whether people with different types of meaning systems adjust differently to the experience of a serious disease.

\section{References}

Albaugh, J. A. (2003). Spirituality and life-threatening illness: A phenomenologic study. Oncology Nursing Forum, 30, 593-598. http://dx.doi .org/10.1188/03.ONF.593-598

Aldwin, C. M., Park, C. L., Jeong, Y.-J., \& Nath, R. (2014). Differing pathways between religiousness, spirituality, and health: A selfregulation perspective. Psychology of Religion and Spirituality, 6, 9-21. http://dx.doi.org/10.1037/a0034416

Ardelt, M., Ai, A. L., \& Eichenberger, A. E. (2008). In search for meaning: The differential role of religion for middle-aged and older persons diagnosed with a life-threatening illness. Journal of Religion, Spirituality \& Aging, 20, 288-312. http://dx.doi.org/10.1080/1552803080 2232353

Belzen, J. A. (2004). Spirituality, culture and mental health: Prospects and risks for contemporary psychology of religion. Journal of Religion and Health, 43, 291-316. http://dx.doi.org/10.1007/s10943-004-4298-4

Berghuijs, J., Pieper, J., \& Bakker, C. (2013). Being 'spiritual' and being 'religious' in Europe: Diverging life orientations. Journal of Contemporary Religion, 28, 15-32. http://dx.doi.org/10.1080/13537903.2013 .750829

Blow, A. J., Swiecicki, P., Haan, P., Osuch, J. R., Symonds, L. L., Smith, S. S., . . . Boivin, M. J. (2011). The emotional journey of women experiencing a breast abnormality. Qualitative Health Research, 21, 1316-1334. http://dx.doi.org/10.1177/1049732311405798

Braun, V., \& Clarke, V. (2006). Using thematic analysis in psychology. Qualitative Research in Psychology, 3, 77-101. http://dx.doi.org/10 .1191/1478088706qp063oa

De Bruin, E. J., van Dijk, M., \& Duivenvoorden, H. J. (1996). Assessing adjustment to cancer: The Health and Disease Inventories (HDI). Lisse, the Netherlands: Swets \& Zeitlinger.

de Jager Meezenbroek, E., Garssen, B., Van den Berg, M., Tuytel, G., Van Dierendonck, D., Visser, A., \& Schaufeli, W. B. (2012). Measuring spirituality as a universal human experience: Development of the Spiritual Attitude and Involvement List (SAIL). Journal of Psychosocial Oncology, 30, 141-167. http://dx.doi.org/10.1080/07347332.2011.65 1258

Donders, J. P. H. (2004). Narratieve reconstructie bij mensen met kanker. [Narrative reconstruction in people with cancer] (Unpublished doctoral dissertation). Tilburg University, the Netherlands.

Ferrell, B. R., Grant, M., Funk, B., Otis-Green, S., \& Garcia, N. (1998). Quality of life in breast cancer. Part II: Psychological and spiritual well-being. Cancer Nursing, 21, 1-9. http://dx.doi.org/10.1097/000 02820-199802000-00001

Gall, T. L., \& Cornblat, M. W. (2002). Breast cancer survivors give voice: A qualitative analysis of spiritual factors in long-term adjustment. Psycho-Oncology, 11, 524-535. http://dx.doi.org/10.1002/pon.613

Garssen, B., Visser, A., \& Uwland-Sikkema, N. (2015). Was religiousness/ spirituality divided into typologies or strata? Journal of Religion and Health, 54, 1266-1267. http://dx.doi.org/10.1007/s10943-014-9865-8

Gockel, A. (2009). Spirituality and the process of healing: A narrative study. International Journal for the Psychology of Religion, 19, 217 230. http://dx.doi.org/10.1080/10508610903143248

James, A., \& Wells, A. (2003). Religion and mental health: Towards a cognitive-behavioural framework. British Journal of Health Psychology, 8, 359-376. http://dx.doi.org/10.1348/135910703322370905

Klemmack, D. L., Roff, L. L., Parker, M. W., Koenig, H. G., Sawyer, P., \& Allman, R. M. (2007). A cluster analysis typology of religiousness/ spirituality among older adults. Research on Aging, 29, 163-183. http:// dx.doi.org/10.1177/0164027506296757

McIntosh, D. N. (1995). Religion-as-schema, with implications for the relation between religion and coping. International Journal for the Psychology of Religion, 5, 1-16. http://dx.doi.org/10.1207/s15327 582ijpr0501_1 
Molzahn, A., Sheilds, L., Bruce, A., Stajduhar, K., Makaroff, K. S., Beuthin, R., \& Shermak, S. (2012). People living with serious illness: Stories of spirituality. Journal of Clinical Nursing, 21, 2347-2356. http://dx.doi.org/10.1111/j.1365-2702.2012.04196.x

Palinkas, L. A., Horwitz, S. M., Green, C. A., Wisdom, J. P., Duan, N., \& Hoagwood, K. (2015). Purposeful sampling for qualitative data collection and analysis in mixed method implementation research. Administration and Policy in Mental Health and Mental Health Services Research, 42, 533-544. http://dx.doi.org/10.1007/s10488-013-0528-y

Pargament, K. I. (1997). The psychology of religion and coping: Theory, research, practice. New York, NY: Guilford Press.

Park, C. L. (2010). Making sense of the meaning literature: An integrative review of meaning making and its effects on adjustment to stressful life events. Psychological Bulletin, 136, 257-301. http://dx.doi.org/10.1037/ a0018301

Park, C. L. (2013). The meaning making model: A framework for understanding meaning, spirituality, and stress-related growth in health psychology. The European Health Psychologist, 15, 40-47.

Park, C. L., \& Edmondson, D. (2011). Religion as a quest for meaning. Paper presented at the 4th Annual Herzlyia Symposium on Personality and Social Psychology: The Social Psychology of Meaning, Mortality, and Choice, Herzliya, Israel.

Park, N. S., Lee, B. S., Sun, F., Klemmack, D. L., Roff, L. L., \& Koenig, H. G. (2013). Typologies of religiousness/spirituality: Implications for health and well-being. Journal of Religion and Health, 52, 828-839. http://dx.doi.org/10.1007/s10943-011-9520-6

Peteet, J. R., \& Balboni, M. J. (2013). Spirituality and religion in oncology. CA: A Cancer Journal for Clinicians, 63, 280-289. http://dx.doi.org/10 $.3322 /$ caac. 21187

Polzer, R. L., \& Miles, M. S. (2007). Spirituality in African Americans with diabetes: Self-management through a relationship with God. Qualitative Health Research, 17, 176-188. http://dx.doi.org/10.1177/104 9732306297750

Reed, P. G. (1992). An emerging paradigm for the investigation of spirituality in nursing. Research in Nursing \& Health, 15, 349-357. http:// dx.doi.org/10.1002/nur.4770150505

Remondes-Costa, S., \& Lopes, R. G. (2014). Spirituality as a search for meaning to the experience of breast cancer: Phenomenological and existential analysis. Psycho-Oncology, 23(Suppl. 3), 190-190. http://dx .doi.org/10.1111/j.1099-1611.2014.3695

Riley, B. B., Perna, R., Tate, D. G., Forchheimer, M., Anderson, C., \& Luera, G. (1998). Types of spiritual well-being among persons with chronic illness: Their relation to various forms of quality of life. Archives of Physical Medicine and Rehabilitation, 79, 258-264. http://dx .doi.org/10.1016/S0003-9993(98)90004-1

Roh, S., Lee, Y. S., Lee, J. H., \& Martin, J. I. (2014). Typology of religiosity/spirituality in relation to perceived health, depression, and life satisfaction among older Korean immigrants. Aging \& Mental Health, 18, 444-453. http://dx.doi.org/10.1080/13607863.2013.848837

Salas-Wright, C. P., Vaughn, M. G., Hodge, D. R., \& Perron, B. E. (2012) Religiosity profiles of American youth in relation to substance use, violence, and delinquency. Journal of Youth and Adolescence, 41, 1560-1575. http://dx.doi.org/10.1007/s10964-012-9761-z

Salsman, J. M., Pustejovsky, J. E., Jim, H. S. L., Munoz, A. R., Merluzzi, T. V., George, L., . . Fitchett, G. (2015). A meta-analytic approach to examining the correlation between religion/spirituality and mental health in cancer. Cancer, 121, 3769-3778. http://dx.doi.org/10.1002/cncr .29350

Silberman, I. (2005). Religion as a meaning system; Implications for the new millennium. Journal of Social Issues, 61, 641-663. http://dx.do .org/10.1111/j.1540-4560.2005.00425.x

Spinhoven, P., Ormel, J., Sloekers, P. P. A., Kempen, G. I. J. M., Speckens, A. E. M., \& Van Hemert, A. M. (1997). A validation study of the Hospital Anxiety and Depression Scale (HADS) in different groups of Dutch subjects. Psychological Medicine, 27, 363-370. http://dx.doi.org/ 10.1017/S0033291796004382

Tanyi, R. A., \& Werner, J. S. (2008). Women's experience of spirituality within end-stage renal disease and hemodialysis. Clinical Nursing Research, 17, 32-49. http://dx.doi.org/10.1177/1054773807311691

Trevino, K. M., Archambault, E., Schuster, J. L., Hilgeman, M. M., \& Moye, J. (2011). Religiosity and spirituality in military veteran cancer survivors: A qualitative perspective. Journal of Psychosocial Oncology, 29, 619-635. http://dx.doi.org/10.1080/07347332.2011.615380

Unterrainer, H. F., Ladenhauf, K. H., Wallner-Liebmann, S. J., \& Fink, A (2011). Different types of religious/spiritual well-being in relation to personality and subjective well-being. International Journal for the Psychology of Religion, 21, 115-126. http://dx.doi.org/10.1080/ 10508619.2011.557003

Received August 11, 2016

Revision received August 6, 2017

Accepted December 3, 2017 